\title{
Effect of Coagulants on the Yield and Quality of Chhana and Rasogolla
}

\author{
Jahura Begum ${ }^{1}$, Md. Nurul Islam ${ }^{1}$, Md. Harun-ur-Rashid ${ }^{1}$, Md. Nozmul Hasssan $^{1}$, Md. Zakirul Islam $^{1}$, Md.Mustafizur Rahman $^{2}$
} and Mohammad Shohel Rana Siddiki ${ }^{1 *}$

10.18805/ajdfr.DR-139

\begin{abstract}
A study was carried out to investigate the effect of different coagulants on the recovery of milk solids, yield and sensory quality of Chhana and the resultant Rasogolla. Six type of coagulants comprising of sour whey $(0.5 \%, 1.0 \%$ acidity), citric acid ( $0.5 \%, 1.0 \%$ acidity) and blend of sour whey and citric acid $(0.5 \%, 1.0 \%$ acidity) were used to prepare Chhana followed by sweet meat Rasogolla. The nonsignificant yield of chhana was found by the use of different coagulants; however it had a significant influence on the fat and total solids (TS) recoveries ranges from 90.5 to $93.8 \% ; 42$ to $44 \%$ of milk for chhana, respectively. The highest mean yield, fat recovery and TS recovery were recorded for B type chhana prepared using $1 \%$ sour whey as coagulant. Rasogollas prepared using varying coagulants did not have any significant influence on any of the sensory attributes of product studied. Rasogolla prepared from chhana made using $1 \%$ sour whey as coagulant had the highest overall sensory score. It is recommended to employ sour whey with $1.0 \%$ of titratable acidity as coagulating agent in the preparation of Rasogolla.
\end{abstract}

Key words: Coagulant, Chhana, Rasogolla, Yield, Sensory quality Asian Journal Of Dairy and Food Research (2019)

\section{INTRODUCTION}

$R^{\prime}$ asogolla is one of the most popular delicious and nutritious products among all sweetmeats being produced in Bangladesh (Mannan et al., 1995). It contains fairly high protein, fat, minerals especially $\mathrm{Ca}$ and $\mathrm{P}$ together with fat-soluble vitamins A, D, E and K (Prajapati et al., 2011). On all festive occasions, Rasogolla is the widely consumed sweetmeat by people of all age groups. The social usage of Rasogolla bears a great significance in each sphere of life such as the Holy Eid, Puja and the birthday parties; the marriage ceremony cannot be presumed to be held without serving this sweetmeat (Islam et al., 2003). In the rural areas of Bangladesh, the Ghosh (sweetmeat makers) or milkman prepares and sells Rasogolla.

The pre-requisite for producing excellent quality of Rasogolla sweetmeat is the availability of high-quality chhana. The food value of Rasogolla largely depends upon the milk constituents recovered in chhana when prepared from milk. In general, cow milk chhana is associated with a soft body and smooth texture; such quality is preferred for preparation of high quality Rasogolla (De and Ray, 1954; Joshi et al., 1991; Ravichandra et al., 1997). Several studies have suggested that cow milk with $4.0 \%$ fat is recommended for the preparation of Rasogolla compared to other milks; the product obtained from cow milk is soft and spongy (Bhattacharya and Raj, 1980; Soni et al., 1980; Bandyopadhyay et al., 2005). The hardness of Rasogolla is mainly influenced by the fat content of standardized milk, Solids not fat (SNF) of milk, acidity of whey at coagulation and the moisture content of chhana (Ravichandra et al., 1997).

The type and strength of coagulant used in chhana making plays a vital role in determining its quality. Citric
'Department of Dairy Science, Bangladesh Agricultural University, Mymensingh-2202, Bangladesh

${ }^{2}$ Deputy Director, Bangladesh Inland Water Transport Authority (BIWTA), Bangladesh

Corresponding Author: Mohammad Shohel Rana Siddik, Department of Dairy Science, Bangladesh Agricultural University, Mymensingh-2202, Bangladesh, Email: msrsiddiki@bau.edu.bd

How to cite this article: Begum, J., Islam, M.N., Harun-ur-Rashid, M., Hasssan, N., Islam, M.Z., Rahman M.M. and Siddiki, M.S.R. (2019). Effect of Coagulants on the Yield and quality of Chhana and Rasogolla. Asian Journal of Dairy and Food Research, 38(3): 186-190.

\section{Source of support: Nil.}

Conflict of interest: None

Submitted:23-08-2019 Accepted:01-10-2019 Published: 15-10-2019

acid has been used by most of the investigators for the preparation of chhana and resultant Rasogolla (Sharma et al., 1991; Pandey et al., 2004). Sour whey is easily available serving as a low-cost coagulant. It has been used for the production of soft bodied chhana, suitable for Rasogolla making (Mahanta, 1964; Srinivasan and Anantakrishnan, 1964). Likewise, satisfactory quality chhana has been obtained through use of $1.0 \%$ citric acid solution (Kumar et al., 2007). The yield of chhana depends mainly on the TS content of milk, milk solids recovery in chhana and the moisture retention in chhana (Ray and De, 1953; De, 1980). Bhattacharya and Raj (1980) recommended keeping 55.0-58.0\% moisture in chhana to be obtained good quality Rasogolla. Therefore, the study was conducted to select the coagulant which performs best in the preparation of good quality chhana and resultant Rasogolla. 


\section{Materials and methods}

\section{Milk}

Raw cow milk was collected from Bangladesh Agricultural University (BAU) Dairy Farm, Mymensingh, Bangladesh and standardized to $4.0 \%$ fat using skim milk separated from the same milk.

\section{Coagulants}

Food grade citric acid (RFCL Ltd., India), sour whey was collected from Rasogolla making shop Krishna Cabin, Mymensingh, Bangladesh. In order to standardize the whey up to desired acidity level, both fresh $(0.42 \%$ acidity) and 3 days old whey $(0.61 \%$ acidity) was collected. Sour whey was not pasteurized and used directly to make chhana. The six types of coagulants were used as follows:

\section{Wheat flour, Sugar and Cardamom}

Soft wheat flour (ACI Pure, Dhaka-Bangladesh) and Cane Sugar (Fresh, Dhaka-Bangladesh) and Cardamom were purchased from local market of Bangladesh.

\section{Chhana Preparation}

Chhana was prepared according to the method described by De (1980) with few modifications. For chhana preparation, $1 \mathrm{~L}$ of fresh cow milk (standardized to $4.0 \%$ fat) was heated to $95^{\circ} \mathrm{C}$ temperature and subsequently cooled to $75-80^{\circ} \mathrm{C}$. Afterwards, different coagulants were slowly added to the milk with continuous stirring till complete coagulation occurred as indicated by clear greenish whey. The coagulated

Table 1: Type strength of coagulants used in preparing chhana

\begin{tabular}{llllll}
\hline \multicolumn{2}{l}{ Sour whey } & \multicolumn{2}{l}{ Citric acid } & \multicolumn{2}{l}{ Sour whey + Citric acid } \\
\hline A & B & C & D & E & F \\
$0.5 \%$ & $1.0 \%$ & $0.5 \%$ & $1.0 \%$ & $0.5 \%$ & $1.0 \%$ \\
\hline
\end{tabular}

Per cent indicates titratable acidity as Lactic acid mass was kept undisturbed for the complete coagulation of milk and allowed to cool up to $37^{\circ} \mathrm{C}$. Chhana was then separated from whey by filtering through a muslin cloth for about 2-3 hour for visible cessation of drainage of whey. Finally, the chhana obtained from each lot was collected and weighed to note the yield.

\section{Rasogolla preparation}

Rasogolla was prepared according to the method of Bhattacharya and Raj (1980) with few modifications. The chhana was mixed with wheat flour $(5.0 \%, \mathrm{w} / \mathrm{w})$ and kneaded properly to make uniform and smooth dough. Chhana dough was divided into small pieces of $10 \pm 2 \mathrm{~g}$ and rolled between the palms to obtain smooth balls, without cracks. Sugar syrup of $60.0 \%$ was prepared by dissolving requisite amount of sugar in potable water. In each trial, $1.5 \mathrm{~L}$ sugar solution was used for cooking and $1.0 \mathrm{~L}$ for soaking. All sugar syrups were clarified by adding some quantity of raw milk during boiling and filtered through a muslin cloth. Previously formed chhana balls were gently dropped into the boiling syrup contained in Karahi. After a few seconds, the foam was formed which covered the floating balls. The mild temperature was regulated as the balls were constantly covered with foam. Some quantity of water was sprinkled during continued boiling of sugar syrup to maintain the sugar syrup concentration. Complete cooking of chhana balls was accomplished within 20-30 minutes. The balls were swollen to about double the original size. Finally, the balls were transferred to the clarified hot sugar syrup having $40.0 \%$ strength for soaking and 2-3 cardamom pieces were added to the sugar syrup and cooled down to room temperature or below.

\section{Sensory evaluation of Rasogolla}

The sensory scoring of product was carried out by an expert panel of six judges from the Department of Dairy Science, Bangladesh Agricultural University, Mymensingh,

Table 1: Effect of coagulants and their strength on the chemical composition of chhana

\begin{tabular}{|c|c|c|c|c|c|c|c|}
\hline \multirow[b]{2}{*}{ Parameters } & \multicolumn{6}{|l|}{ Type of chhana } & \multirow[b]{2}{*}{$C D$} \\
\hline & $A$ & $B$ & $C$ & $D$ & $E$ & $F$ & \\
\hline Moisture (\%) & $57.80^{\mathrm{a}} \pm 0.17$ & $56.10^{d} \pm 1.00$ & $57.52^{\mathrm{b}} \pm 0.26$ & $56.03^{d} \pm 0.20$ & $57.23^{c} \pm 2.00$ & $56.13^{d} \pm 0.30$ & 1.66 \\
\hline Fat (\%) & $21.68^{d} \pm 1.75$ & $22.40^{\mathrm{a}} \pm 3.00$ & $21.94^{b c d} \pm 0.81$ & $22.25^{\mathrm{ab}} \pm 2.50$ & $21.86^{\mathrm{cd}} \pm 0.91$ & $22.05^{b c} \pm 0.50$ & 3.26 \\
\hline Protein (\%) & $17.13^{c} \pm 0.38$ & $17.50^{\mathrm{a}} \pm 0.56$ & $17.08^{\mathrm{c}} \pm 0.80$ & $17.56^{\mathrm{a}} \pm 0.60$ & $17.27^{b} \pm 0.80$ & $17.63^{\mathrm{a}} \pm 1.35$ & 1.43 \\
\hline Ash (\%) & $1.50^{C} \pm 0.26$ & $1.60^{b} \pm 0.40$ & $1.50^{c} \pm 0.66$ & $1.80^{\mathrm{a}} \pm 0.56$ & $1.60^{b} \pm 0.40$ & $1.70^{\mathrm{a}} \pm 0.70$ & 0.92 \\
\hline Lactose (\%) & $1.90^{c} \pm 1.15$ & $2.40^{\mathrm{a}} \pm 1.05$ & $2.00^{\mathrm{b}} \pm 1.19$ & $2.20^{b} \pm 2.65$ & $2.50^{c} \pm 1.50$ & $2.40^{\mathrm{a}} \pm 2.00$ & 3.00 \\
\hline Yield (\%) & $16.90 \pm 1.00$ & $16.70 \pm 1.33$ & $16.70 \pm 1.00$ & $16.67 \pm 1.36$ & $16.71 \pm 1.00$ & $16.67 \pm 1.53$ & - \\
\hline Fat recovery (\%) & $90.50^{c} \pm 0.19$ & $93.80^{\mathrm{a}} \pm 0.61$ & $91.61^{b c} \pm 0.35$ & $92.65^{\mathrm{ab}} \pm 0.62$ & $90.54^{c} \pm 1.30$ & $91.87^{b} \pm 0.65$ & 1.26 \\
\hline Total solids recovery (\%) & $56.38^{c} \pm 0.34$ & $58.82^{\mathrm{a}} \pm 0.34$ & $56.73^{b c} \pm 0.29$ & $58.59^{\mathrm{a}} \pm 0.51$ & $57.18^{b} \pm 0.12$ & $58.49^{\mathrm{a}} \pm 0.49$ & 0.66 \\
\hline
\end{tabular}

NS = Non significant

Values with different superscripts ( $a, b, c$ and $d$ ) are significantly different at $5 \%$ level

$\mathrm{A}=$ Sour whey with $0.5 \%$ acidity, $\mathrm{B}=$ Sour whey with $1.0 \%$ acidity, $\mathrm{C}=$ Citric acid with $0.5 \%$ acidity, $\mathrm{D}=$ Citric acid with $1.0 \%$ acidity, $\mathrm{E}=$ Sour whey + citric acid with $0.5 \%$ acidity, $\mathrm{F}=$ Sour whey + citric acid with $1.0 \%$ acidity

$\mathrm{CD}=$ Critical difference

Average TS of milk $=12.5 \%$ 
Bangladesh. The samples of Rasogolla were scored using 9-point hedonic scale for sensory attributes such as colour and appearance, flavour and taste, body and texture, sweetness and overall acceptability.

\section{Chemical analysis}

Moisture, fat, carbohydrate and ash content of milk, chhana and Rasogolla were determined as per AOAC, 2003 method. The protein content of the products was determined by Kjeldhal methodand the acidity was analysed by acid-base titration method (Aggrawala and Sharma, 1961).

\section{Statistical analysis}

Data collected on different parameters were subjected to statistical analysis. Analysis Variance (ANOVA) test was done to find out the statistical differences between different groups with the help of wasp2 (Web Agri Stat Package, version 2.0) computer program.

\section{Results AND discussion}

\section{Effect of Coagulants on the Chemical Composition of Chhana}

The moisture content of chhana made using different coagulants differed significantly $(p<0.01)$ from each other. The highest and least moisture content was associated with $0.5 \%$ SW chhana and $1.0 \%$ CA, respectively. The moisture content of chhana significantly decreased $(p<0.01)$ with increased strength of coagulants (i.e. $1.0 \mathrm{vs.} 0.5 \%$ ) used in the study. Such observation is in agreement with the findings of Bandyopadhyay et al. 2005. The fat content was found higher in the type of chhana where the moisture content was lower. The channa type B, D and $\mathrm{F}$ was showed higher fat content around $22.0 \%$. In case of protein content of chhana differed significantly $(p<0.01)$ among the samples. The highest value was noted in chhana prepared using $1 \%$ SW + CA. Singh et al. 2011 reported protein content of about $18.0 \%$ of chhana, irrespective of the type of coagulants used; a similar value as reported in the present investigation. The maximum ash content was accompanied with chhana prepared using $1 \%$ CA and a time lowest content was found at $0.5 \% \mathrm{SW}$. The result slightly differed with the finding of Singh et al. (2011) who reported average ash content of $1.95 \%$ in chhana, irrespective of the type of coagulants used. The level of lactose was found highest for chhana prepared using $1 \%$ SW + CA and minimum value recorded at $0.5 \%$ SW. The yield of chhana was not significantly differed among the different coagulants used with different strength. The yield of chhana was recorded highest and least for product prepared using $1 \%$ SW and $1 \%$ CA as coagulants, respectively. De (1952) and Bankar et al. (2014) reported that with an increase of 0.1 to $0.13 \%$ titratable acidity in the strength of coagulant, there was a steady decline in the yield of chhana. Sen and De (1984) reported greater yield of chhana when using calcium lactate rather than using citric acid as coagulant. In addition, greater yield of chhana was obtained from calcium lactate coagulant than the chhana obtained from citric acid coagulant (Kumar et al., 2015). Fat as well as TS recovery of chhana differed significantly $(p<0.01)$ when using all of the coagulants of varying strength. The fat and TS recovery in chhana was highest when using $1 \% \mathrm{SW}$. The result regarding fat loss in whey agreed with the chhana made using $1 \%$ citric acid and $2 \%$ lactic acid by other authors (Bandyopadhyay et al., 2005; Bankar et al., 2014).

\section{Effect of Coagulants on the Chemical Composition of Rasogolla}

The chemical quality of Rasogolla as affected by utilizing chhana obtained using coagulants of varying strength is depicted in Table 2. All the chemical constituents of Rasogolla were not significantly $(P>0.05)$ affected by the type of coagulant or their strength except for moisture and carbohydrate content. The highest and least mean values of moisture content were recorded for Rasogolla obtained from chhana made using CA and SW + CA both at $0.5 \%$ strength, respectively. Reddy et al. (2016) reported moisture content of $58.09 \%$ for control Rasogolla; such value was higher than the moisture content obtained in present investigation. According to Bangladesh Standard and Testing Institution (BSTI, 1993) standard moisture content of Rasogolla is $55.0 \%$ (max) which is similar to our findings. In addition, Sengupta et al. (2017) observed the moisture content of $53.0 \%$ in soy-milk based Rasogolla-like product utilizing lactic acid as coagulant. Besides, according to Bhattacharya et al., 1980 prepared Rasogolla with chhana having initial moisture content of 40 , $45,50,55,58,60$ and $65 \%$ and stated about $55-58 \%$ moisture

Table 2: Effect of coagulants and their strength on the chemical composition of Rasogolla

\begin{tabular}{|c|c|c|c|c|c|c|c|}
\hline \multirow[b]{2}{*}{ Parameters } & \multicolumn{6}{|c|}{ Types of Rasogolla } & \multirow[b]{2}{*}{$C D$} \\
\hline & $A$ & $B$ & $C$ & $D$ & $E$ & $F$ & \\
\hline Moisture (\%) & $54.24^{b} \pm 24.90$ & $54.67^{b} \pm 6.85$ & $55.33^{\mathrm{a}} \pm 46.35$ & $54.30^{b} \pm 12.80$ & $51.67^{c} \pm 6.80$ & $54.49^{b} \pm 22.90$ & 1.02 \\
\hline Fat (\%) & $5.27 \pm 2.52$ & $5.60 \pm 4.59$ & $5.90 \pm 2.00$ & $5.47 \pm 1.53$ & $5.83 \pm 1.53$ & $5.77 \pm 2.52$ & - \\
\hline Protein (\%) & $7.23 \pm 3.05$ & $7.55 \pm 4.27$ & $7.67 \pm 2.89$ & $7.38 \pm 6.33$ & $7.53 \pm 2.65$ & $7.57 \pm 4.25$ & - \\
\hline Ash (\%) & $9.42 \pm 0.81$ & $9.63 \pm 0.37$ & $8.82 \pm 0.20$ & $9.50 \pm 0.50$ & $8.86 \pm 0.26$ & $9.69 \pm 0.34$ & - \\
\hline Carbohydrate (\%) & $32.32^{\mathrm{b}} \pm 21.55$ & $31.20^{c} \pm 8.97$ & $30.22^{d} \pm 46.35$ & $32.00^{b} \pm 11.96$ & $34.08^{\mathrm{a}} \pm 7.02$ & $31.20^{c} \pm 20.87$ & 0.56 \\
\hline
\end{tabular}

The values are presented Mean \pm SD

$\mathrm{A}=$ Sour whey with $0.5 \%$ acidity, $\mathrm{B}=$ Sour whey with $1.0 \%$ acidity, $\mathrm{C}=$ Citric acid with $0.5 \%$ acidity, $\mathrm{D}=$ Citric acid with $1.0 \%$ acidity, $\mathrm{E}=$ Sour whey + citric acid with $0.5 \%$ acidity, $F=$ Sour whey + citric acid with $1.0 \%$ acidity

$\mathrm{CD}=$ Critical difference 
in chhana to be optimum for preparation of good quality Rasogolla having round shape, soft body, and maximum spongy texture for atmospheric cooking. The highest fat content was noted for Rasogolla prepared from chhana made using $0.5 \%$ CA coagulants. According to both BSTI standard (1993) and Indian Standard (IS, 1967) fat content of Rasogolla should be minimum $5.0 \%$, which was more or less similar to the result of present investigation. The maximum and minimum protein content was noted for Rasogolla obtained from chhana coagulated using $0.5 \%$ CA and $0.5 \%$ $\mathrm{SW}$, respectively. The maximum ash content was associated with Rasogolla prepared from chhana made using $1 \%$ SW+CA. Thakur et al. (2015) recorded $1.63 \%$ ash for Rasogolla made from chhana prepared using $0.5 \%$ CA coagulant. The maximum and minimum carbohydrate content was noted for Rasogolla prepared from chhana obtained using 0.5\% SW+CA and $0.5 \%$ CA as coagulant respectively. As per BSTI specification (1993), the carbohydrate content of Rasogolla cannot exceed $45.0 \%$.

\section{Effect of Coagulants on the Sensory Quality of Rasogolla}

The results regarding the sensory quality of Rasogolla as affected by chhana prepared using different coagulants are collated in Table 3. All the individual sensory attributes of Rasogolla studied were found to be at par with each other, irrespective of the coagulants used for chhana preparation. It was revealed from Table 3 that there was no significant difference in color and appearance scores of different Rasogolla samples obtained from varying coagulants. The colour and appearance score was recorded as highest and least for Rasogolla prepared from chhana made of using $1 \%$ SW+CA as coagulant. Kumar et al., 2015 did not notice any marked difference in the colour and appearance score of Rasogolla samples prepared from chhana obtained using varying coagulants such as lactic acid, citric acid as well as calcium lactate.

Superior flavour and taste score was associated with Rasogolla sample prepared from chhana made using $1 \%$ CA. Rasogolla prepared from chhana coagulated by $1.0 \%$ of acidity irrespective of coagulant obtained more flavour and taste score than Rasogolla made from chhana coagulated by $0.5 \%$ acidity irrespective of coagulant. Kumar et al. (2015) observed there was no significant difference in the sweetness of different Rasogolla samples obtained from varying coagulants (lactic acid and calcium lactate). The Rasogolla prepared from chhana made using $1 \%$ SW had superior flavour score. Bankar et al. (2014) stated that the chhana made with $1.0 \%$ citric acid and $2.0 \%$ lactic acid had similar flavor scores. The Rasogolla prepared from chhana coagulated with $1 \%$ SW was soft and flimsy which split into pieces when mangled in the mouth. Kumar et al. (2012) did not notice any significant difference in the flavor scores of Rasogolla samples prepared from chhana made using varying coagulants (citric acid, lactic acid and sour whey).

With respect to body and texture, the highest score was associated with Rasogolla made from chhana coagulated using $1 \%$ SW. Kumar et al. (2015) noted that a highly significant difference $(p<0.01)$ in body and texture score of Rasogolla was obtained when using varying coagulants (amount of standardized blend $=1 \mathrm{~kg}$; strength of coagulants: lactic acid and citric acid $=1 \%$ solution; calcium lactate $=4 \%$ ). Bankar et al. (2014) noted superior score for body and texture for Rasogolla made using $1.0 \%$ and $2.0 \%$ lactic acid as coagulant, followed by $1.0 \%$ citric acid. Their finding does not match the findings of the present investigation.

The overall sensory score was found highest for Rasogolla prepared from chhana made using $1 \%$ SW coagulant. Bankar et al. (2014) observed overall acceptability of chhana made with $1.0 \%$ citric acid and $2.0 \%$ lactic acid recorded significantly higher score as compared to other coagulants and their strength. Furthermore, Rao et al. (1989) reported that Rasogolla obtained from cow milk chhana made with 1.0 $\%$ citric acid compared to calcium lactate and lemon water as a coagulant is most acceptable.

\section{Conclusion}

Sour whey is the predominantly used coagulant in preparation of chhana based sweetmeats by the sweetmeat manufacturers in Bangladesh. Based on the present investigation, as far the yield of chhana is concerned, there was no significant difference among the groups. Although, sour whey having $1.0 \%$ lactic acid is a highly suitable coagulant for obtaining chhana which yielded Rasogolla having desired sensory quality conforming to the standards for chemical composition.

Table 3: Effect of coagulants and their strength on the sensory scores of Rasogolla

\begin{tabular}{llllllll}
\hline & \multicolumn{2}{l}{ Types of Rasogolla } & \multicolumn{2}{l}{} & \\
\cline { 2 - 6 } Score for & $A$ & $B$ & $C$ & $D$ & $E$ & $F$ \\
\hline Colour and appearance & $10.75 \pm 1.25$ & $12.13 \pm 1.87$ & $11.50 \pm 1.00$ & $12.13 \pm 0.62$ & $11.50 \pm 0.50$ & $12.38 \pm 0.12$ & - \\
Flavour \& Taste & $7.25 \pm 0.50$ & $8.75 \pm 1.29$ & $7.50 \pm 0.50$ & $8.00 \pm 0.49$ & $7.13 \pm 0.62$ & $8.50 \pm 0.50$ & - \\
Body and texture & $22.75 \pm 3.50$ & $26.33 \pm 3.76$ & $22.88 \pm 2.87$ & $24.88 \pm 2.87$ & $23.75 \pm 2.00$ & $25.63 \pm 0.62$ & - \\
Total score & $75.42 \pm 6.50$ & $86.04 \pm 10.64$ & $77.46 \pm 5.81$ & $83.26 \pm 5.56$ & $76.88 \pm 4.30$ & $85.18 \pm 1.23$ & - \\
\hline
\end{tabular}

Value indicated as Mean \pm SD

$\mathrm{A}=$ Sour whey with $0.5 \%$ acidity, $\mathrm{B}=$ Sour whey with $1.0 \%$ acidity, $\mathrm{C}=$ Citric acid with $0.5 \%$ acidity, $\mathrm{D}=\mathrm{Citric}$ acid with $1.0 \%$ acidity, $\mathrm{E}=$ Sour whey + citric acid with $0.5 \%$ acidity, $\mathrm{F}=$ Sour whey + citric acid with $1.0 \%$ acidity

$C D=$ Critical difference 


\section{References}

Aggarwala AC, Sharma A 1961: A laboratory manual of milk inspection. 4th edn.Asia Publishing House, Bombay, Calcutta, New Delhi, India. p. 345.

AOAC 2003: Official Methods of Analysis (10thedn.). Association of Official Agricultural Chemists. Washington, DC, USA.

Bandyopadhyay M, Chakraborty R, Raychaudhuri U 2005: The effect of coagulants on the texture of chhana (an acid and heat coagulated product made from milk). International Journal of Food Science and Technology 40(8) 799-810.

Bangladesh Standard and Testing Institution (BSTI) 1993: Bangladesh Standard Specification for Rasogolla. BDS 1309. p. 1-5.

Bankar SS, Raziuddin M, Zanjad PN 2014: The influence of different coagulants on yield and sensory quality of cow milk chhana. Indian Research Journal of Extension and Education 14(4) 61-64.

Bhattacharya DC, Raj D 1980: Studies on the production of Rasogolla. Part II. Pressure cooker method. Indian Journal of Dairy Science 33(4) 479-483.

IS: 4079-1967.Specification for canned rasogolla. Indian Standards Institution, New Delhi. De S 1952: Study on desiccation and coagulation of milk in the manufacture and storage of indigenous milk products. M.Sc. Thesis, Bombay University, Mumbai.

DeS 1980: Outlines of dairy technology. Oxford University Press, Delhi. p. 517.

De S, Ray SC 1954: Studies on indigenous method of chhana making. Indian Journal of Dairy Science 7 113-116.

Islam MZ, Rahman SMR, Alam MM, Mannan AKMA 2003: Manufacture of Rassomalai and its quality attributes: An indigenous milk sweetmeat of Bangladesh. Pakistan Journal of Nutrition 2(5) 300-304.

Joshi SV, Majgaonkar SV, Toro VA 1991: Effect of different coagulants on yield and sensory quality of chhana prepared from milk of cow, buffalo and goat. Indian Journal of Dairy Science 44(6) 380-383.

Kumar J, Gupta VK, Kumar B, Kumar S 2012: The influence of varying degree of coagulation temperature on sensory and texture characteristics of chhana butter milk and buffalo milk. Indian Journal of Dairy Science 65(2)129-134.

Kumar J, Gupta VK, Kumar S, Kumar S 2015: Effect of coagulants on the quality of Chhana and rasogolla obtained from admixture of buffalo milk and butter milk. Journal of Food Science and Technology 52(3) 1736-1741.
Kumar S, Dwivedi HB, Yadar SP, Yadav RN 2007. Use of chemical and herbal coagulants in Chhana production from cow milk. Progressive Research 2(1/2) 150.

Mahanta KC 1964: Handbook of Dairy Science, Kitabstan, Allahabad, India. p. 386.

Mannan AK, Hossain MS, Islam MM 1995: Standard of traditionally made Chamcham, Moonda, Rasogolla, Monda, effects of different coagulants milk for Chhana making. Bangladesh Agricultural University, Research Progress 9 306-310.

Prajapati PS, Chavan RS, Jana A, Chavan SR 2011: Rasogolla Ambrosia of Indian: A Review. Beverage and Food World 45(3) 27-30.

Rao MS, Rao MR, Ranganadham M, Rao BVR 1989: Studied on the preparation of chhana from buffalo milk and its suitability for Rasogolla manufacture. Indian Journal of Dairy Science 42(4)810-816.

Ravichandra MN, Mishra HN, Das H 1997: Optimization of process parameters for the production of Rasogolla from cow milk. Journal of Food Science and Technology (Mysore) 34(1) 46-49.

Ray SC, De S 1953: Indigenous dairy products of India-III Chhana. Indian Dairyman 515.

Reddy GMM, Arora P, Chandra R, Singh SS 2016: Production and quality evaluation of Rasogolla prepared from milk with different levels of fat. International Journal of Scientific and Engineering Research 7(8)2084-2086.

Sen DC, De S 1984: Studies on calcium lactate as chhana coagulant. Journal of Food Science and Technology 21 243-244.

Sengupta S, Samanta A, Bhowal J 2017: Effect of different types of coagulating agent on physico-chemical and organoleptic properties of non-dairy rasgolla (Cheese ball). Journal of Microbiology, Biotechnology and Food Sciences.

Sharma DK, Reuter H 1991: A new method of chhana making by ultrafiltration technique. Indian Journal of Dairy Science 4489-95.

Singh PK, Singh OP, Kumar R, Singh AK, Singh NK 2011: Quality of chhana prepared from cow milk by chemical and herbal coagulants. Journal of Dairying, Foods and Home Science 30(3) 155-159.

Soni K, Bandyopadhyay AK, Ganguly NC 1980: Manufacture of Rasogolla from buffalo milk. Indian Journal of Dairy Science 33(3) 357-365.

Srinivasan MR, Anantakrishnan CP 1964: Milk products of India. Indian Council of Agricultural Research, New Delhi.p. 9.

Thakur SN, Kant R, Chandra R 2015: Studies on preparation of rasogollafrom blend of cow milk and soya milk. The Allahabad Farmer LXX (2) 6-9. 